\title{
Effect of the Cultivation Systems and Split Fertilizer Applications on the Growth and Yields of Tatsoi (Brassica rapa subsp. narinosa)
}

\author{
Kartika Kartika ${ }^{1,2}$, Benyamin Lakitan ${ }^{2,3, *}$, Rofiqoh P. Ria ${ }^{2}$ and Hana H. Putri ${ }^{2}$ \\ ${ }^{I}$ Research Center for Biology, National Research and Innovation Agency, Cibinong 16911, Indonesia \\ ${ }^{2}$ College of Agriculture, Universitas Sriwijaya, Inderalaya 30662, Indonesia \\ ${ }^{3}$ Research Center for Sub-optimal Lands, Universitas Sriwijaya, Palembang 30139, Indonesia
}

('Corresponding author's e-mail: blakitan60@unsri.ac.id)

Received: 26 April 2021, revised: 30 May 2021, Accepted: 5 June 2021

\begin{abstract}
Tatsoi [Brassica rapa subsp. narinosa (L.H.Bailey) Hanelt] is a leafy vegetable with potential for cultivation in a riparian wetland ecosystem. The floating culture system has the advantage of ensuring a sufficient water supply in the growing substrate due to the continuous upward water movement caused by capillarity force. This study evaluated the responses of the tatsoi plant to split fertilizer applications under conventional cultivation and floating culture systems. The fertilizer treatments consisted of control (F0), single (F1), split into 2 (F2), split into 3 (F3) or split into 4 applications (F4). The results showed that early growth of tatsoi was better using floating culture than the conventional system. However, tatsoi adapted well to conventional and floating culture systems as long as sufficient nutrients were available. A single application of $6 \mathrm{~g}$ NPK fertilizer $(16: 16: 16 \mathrm{v} / \mathrm{v} / \mathrm{v})$ at transplanting provided sufficient nutrients, as indicated by the number of leaves, total leaf area, canopy area, stem dry weight, and leaf dry weight at harvest. The leaf SPAD values in the tatsoi plants were higher in the floating culture system than in the conventional system at 14 and 20 DAT fertilized with a 4-split application. Transplanting occurred 14 days after seed planting (DAP), and harvest occurred 49 days later. A quadratic regression model using leaf length $(\mathrm{L})$, leaf width $(\mathrm{W})$, or $\mathrm{L} \times \mathrm{W}$ as predictors was reliable for non-destructive leaf area estimation in the tatsoi plant. It is recommended for farmers to apply a single NPK fertilizer at the rate of $6 \mathrm{~g} / \mathrm{plant}$ to achieve an optimum yield in tatsoi cultivated using a conventional or floating culture system.
\end{abstract}

Keywords: Conventional cultivation, Floating culture, Leaf area estimation, Riparian wetland, Split fertilizer application

\section{Introduction}

Tatsoi (Brassica rapa subp. narinosa) is a leafy vegetable and a source of vitamins A, C, E, high quality protein, carotenoids [1] and antioxidant enzymes such as superoxide dismutase, catalase and soluble peroxidase [2]. Tatsoi is adaptive to a wide range of environmental conditions. Since tatsoi is a short-lived leafy vegetable, it is potentially cultivated in riparian wetlands using a floating culture system.

The tatsoi plant is not only a nutritious and fast-growing leafy vegetable but also belongs to the Brassica rapa species which has significant economic importance around the world $[3,4]$ and is commonly selected as the main vegetable cultivated in sophisticated indoor commercial facilities, from controlled hydroponic systems to plant factory systems [4,5]. However, the tatsoi plant can also be grown conventionally on dry land or on flooded land using a floating culture system at a much lower cost [6].The intensity of agricultural activities in the riparian ecosystem is very low, caused by the unpredictable start and duration of floods during the rainy season and drought stress during the dry season [7]. Riparian wetland in Indonesia is characterized by acidic soil with limited nutrient availability [8,9]. The addition of fertilizer is required for sufficient nutrients for optimum growth. Fertilizer application is necessary for obtaining good quality and high yield [10]. Splitting fertilizer application could increase yields by distributing nutrient across stages of plant growth, increasing nutrient use efficiency, and minimizing agrochemical leakage to open water [8]. Thus, splitting fertilizer applications is beneficial for establishing an ecologically friendly plant cultivation practice.

Floating culture has been introduced in riparian wetlands. The floating culture is a production practice using floating beds constructed from locally available biomaterials $[11,12]$. Floating beds have 
been created using used plastic bottles for vegetable cultivation [11,13-15]. From an economic, ecological, social, and cultural standpoint, the floating culture was advantageous [16]. The objective of this study was to evaluate the response of tatsoi cultivated conventionally versus in a floating culture system and the effectiveness of split fertilizer applications towards growth and yield performance.

\section{Materials and methods}

The study was carried out in a tropical lowland climate at an outdoor research facility in Jakabaring (104 46' 44' E; 3 ${ }^{\circ} 01$ ' 35' S), Palembang, South Sumatra, Indonesia. The altitude is less than $15 \mathrm{~m}$ above sea level. The study was conducted during the dry season, July to September in 2020 . The average temperature was 34 degrees Celsius, and the relative humidity was around $75 \%$. The plant material used was the F1 Ta-Ke-Cai variety. Prior to sowing, seeds were soaked in tap water and placed on wet tissue in a covered petri dish for $24 \mathrm{~h}$. Germinated seeds were planted in seedling trays filled with a mixture media of soil and compost $(1: 1 \mathrm{v} / \mathrm{v})$. Seedlings were transplanted from the tray to plastic pots at 14 days after seed planting (DAP). The dimensions of the pot are $27.5 \mathrm{~cm}$ in upper diameter, $20 \mathrm{~cm}$ in base diameter, and $20 \mathrm{~cm}$ in height. The pots were filled with soil-compost mix $(2: 1 \mathrm{v} / \mathrm{v})$ up to $15 \mathrm{~cm}$ height, equivalent to $6.2 \mathrm{~L} /$ pot. The seedlings had 2 true leaves with the height of $2 \mathrm{~cm}$ at transplanting, not including cotyledon leaves. Each pot had 4 bottom holes. In conventional cultivation, the holes function to enable water drainage. Reversely, in the floating culture system, the bottom holes function to facilitate upward water movement due to the capillarity force, from the available water underneath the pot into the growing media within the pots $[11,13]$. Four side holes were made for the direct outflow of excess water above the substrate surface during heavy rain.

A floating culture system was conducted in experimental ponds. Each pond can accommodate 3 floating rafts with a dimension of $2.0 \times 1.0 \times 0.078 \mathrm{~m}^{3}$. It required 55 units of $1500 \mathrm{~mL}$ used plastic (polyethylene terephthalate, PET) bottles for the construction of each raft. The emptied bottles functioned as floaters. The material used for the exoskeleton frame of the raft has been modified from polyvinyl chloride (PVC) pipe to bamboo trunk to reduce costs, as requested by local farmers, i.e., targeted adopters of this low-cost floating culture system.

The total weight of all the substrate-filled pots was managed to create a condition where the upper surface of the raft was submerged at a depth of 1 to $2 \mathrm{~cm}$ below the water surface, so the bottom of the growing substrate was immersed to a depth of $1.5 \mathrm{~cm}$. Each pot has 4 bottom holes, which enable direct contact between the bottom part of the growing substrate and the water surface.

The conventional system used a similar growing substrate and pot size. Tatsoi plants were watered twice daily (at 7 am and $5 \mathrm{pm}$ ) in a conventional system; however, no watering was needed for the floating culture. The pots were arranged based on the factorial randomized block design. The first factor was cultivation systems, i.e., conventional and floating culture. The second factor was the split fertilizer application, which consisted of a control with no fertilizer application (F0), single (F1), split to 2 (F2), split to 3 (F3) and split to 4 applications (F4). The rate of fertilizer used was similar at $6 \mathrm{~g}$ NPK $(16: 16: 16)$ for all split application treatments (Table 1). Each treatment consisted of 3 replications. Each replication consisted of 3 pots.

Table 1 Rates and schedule of each fertilizer application.

\begin{tabular}{cccccc}
\hline \multirow{2}{*}{$\begin{array}{c}\text { Split application } \\
\text { treatment }\end{array}$} & \multicolumn{5}{c}{ Rate at each application (g) } \\
\cline { 2 - 6 } & 0 DAT & 10 DAT & 14 DAT & 18 DAT & 28 DAT \\
\hline F0 & 0 & 0 & 0 & 0 & 0 \\
F1 & 6 & 0 & 0 & 0 & 0 \\
F2 & 3 & 0 & 3 & 0 & 0 \\
F3 & 2 & 0 & 2 & 0 & 2 \\
F4 & 1.5 & 1.5 & 0 & 1.5 & 1.5 \\
\hline
\end{tabular}

$\mathrm{DAT}=$ Days after seedlings were transplanted. F0 $=$ unfertilized, F1 $=$ single, $\mathrm{F} 2=$ split to $2, \mathrm{~F} 3=$ split to 3 and F4 = split to 4 applications. 
The numbers of leaves, leaf area, SPAD value, and canopy area were determined. The SPAD value was measured using a chlorophyll meter (SPAD 502 Plus, Konica-Minolta, Osaka, Japan), and the canopy area was measured using a digital image analyzer developed by Easlon and Bloom [17]. The destructive observation was conducted every week to assess plant biomass and measure the morphological dimension of collected leaves. This destructive observation did not affect the remaining plants since each plant was planted in each individual pot and the spacing within the plant population could be rearranged accordingly. Plant roots, stems and leaves were separated and weighed. Dry weight was determined after samples were dried in a convection oven at $70{ }^{\circ} \mathrm{C}$ until a constant weight was obtained.

Leaf petiole length, midrib length, leaf width, and leaf thickness were collected and used as predictors in developing the leaf area estimation model. The measurements were made on more than 500 leaves were selected, varied from the smallest to the largest amongst all harvested leaves in this experiment. Leaf thickness was measured using a digital caliper (Taffware SH20). These 4 single predictors plus 1 combined leaf length $\times$ width as a double predictor were used in this study; therefore, in total, there were 5 predictors used. All 5 predictors were tested using quadratic regression for estimating leaf area. Values of the estimated area of every single leaf were validated by comparing each of them with directly measured leaf area using digital image analysis software (LIA32, developed by Kazukiyo Yamamoto, Nagoya University, Japan). The accuracy of each model was evaluated based on the value of the coefficient of determination $\left(\mathrm{R}^{2}\right)$.

The directly measured leaf area was used in the calculation of the leaf area index (LAI), specific leaf area (SLA), and leaf area ratio (LAR). The estimated leaf area generated using the regression models will be used for the growth analysis studies requiring sequential or time-wise measurements on the same intact leaves such as relative leaf expansion rate [18,19].

Statistical software (Statistical Analysis System version 9.0 for Windows, SAS Institute, Cary, NC) was used to perform analysis of variance and mean comparisons on the collected data. Development and validation of leaf area estimation models were done using quadratic regression. Periodical measurements over time were presented using histogram charts.

\section{Results and discussion}

\section{Effects of cultivation systems and split fertilizer applications}

Only during early vegetative growth (14 and 20 DAT) were more leaves observed in tatsoi plants cultivated with floating culture than in the conventional system, whereas the number of leaves at and after 26 DAT was statistically similar between the 2 cultivation practices. The effect of fertilizer application was detected during the later growth stage, which commenced from 26 to 35 DAT. This effect was similar between single and all split fertilizer applications (Figure 1). As a result, split fertilizer application in tatsoi plants did not increase yields for farmers, most likely due to the tatsoi plants' short growing cycle, i.e., harvested within 35 DAT. In floating culture, a single fertilizer applied at the time of transplanting (F1) consistently exhibited a higher total leaf area than control plant from 14 to 35 DAT; meanwhile, in the conventional system, a clear difference in total leaf area was revealed at a later growth stage, i.e., 35 DAT. (Figure 2). There is a difference between the total leaf area and the canopy area. Total leaf area is the total area of all the leaves in each plant, while canopy area is the perpendicular projection of the plant's canopy on a flat surface underneath the plant. Therefore, the difference between total leaf area and canopy area represents the degree of overlapping amongst leaves within a plant canopy. Tatsoi developed organized layers of spoon-shaped leaves to form a thick rosette and orderly rounded canopy. In the case of tatsoi plants cultivated using floating culture, the canopy areas of NPK fertilized tatsoi plants were significantly larger than those of unfertilized control plants at 28 DAT and later growth stages; however, there was no significant difference in canopy area amongst split fertilizer treatments. Meanwhile, fertilizer application did not increase canopy area, except for the plants treated with NPK fertilizer split to 4 applications (F4) at 28 DAT and a single application (F1) at 35 DAT (Figure 3).

At early growth (14 and 20 DAT), stem and leaf dry weights of tatsoi cultivated with floating culture were higher than those grown with conventional cultivation in some combinations of split fertilizer application and plant age; however, at late growth stages (28 and 35 DAT) in non-fertilized plants, leaf dry weights were lower in plants cultivated with floating culture. Meanwhile, root dry weight was not significantly different between the 2 cultivation practices (Table 1). 

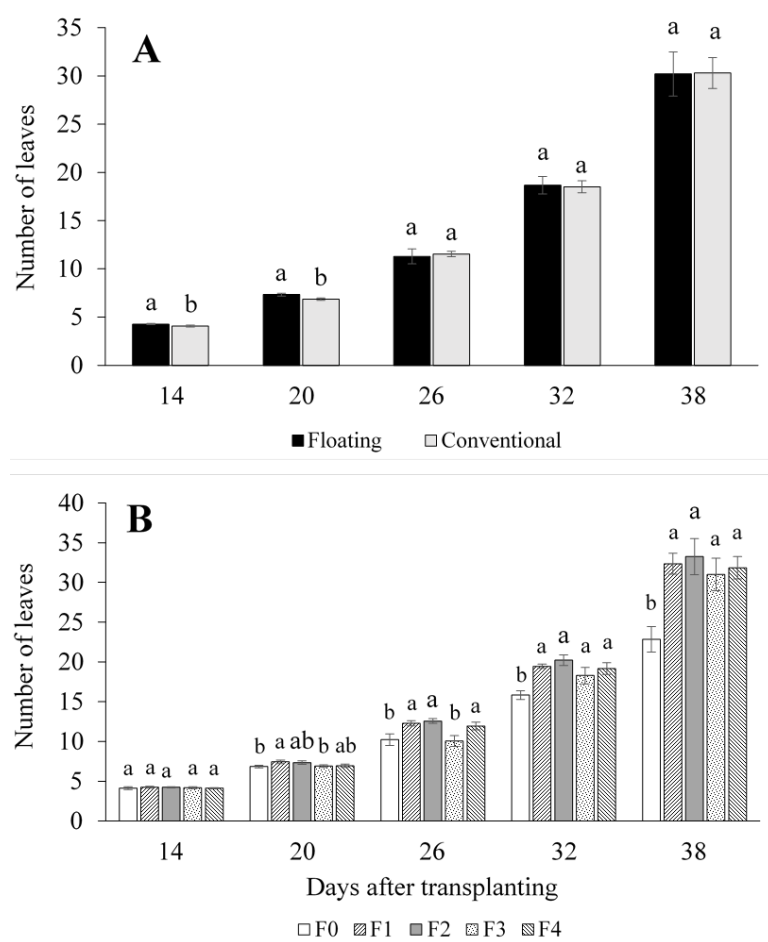

Figure 1 A) The number of leaves in tatsoi grown in different cultivation systems, and B) the fertilizer application split. F0 = unfertilized, F1 $=$ single, F2 $=$ split into 2, F3 $=$ split into 3 and F4 = split into 4 applications. Vertical bars represent standard deviations. Different letters within each clustered column from 14 to 38 DAT are significantly different at $p<0.05$.
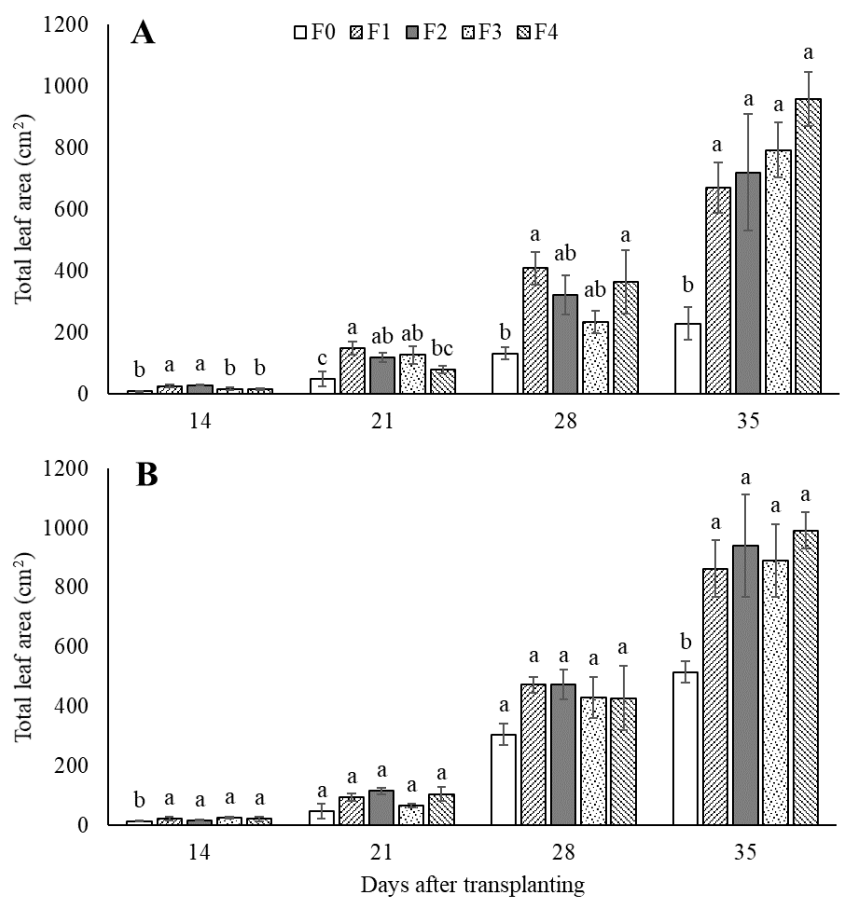

Figure 2 A) Total leaf area per plant in tatsoi grown in floating culture systems versus B) conventional system. F0 = unfertilized, F1 = single, F2 = split into 2, F3 = split into 3 and F4 = split into 4 applications. Vertical bars represent standard deviations. Different letters within each clustered column from 14 to 35 DAT are significantly different at $p<0.05$. 

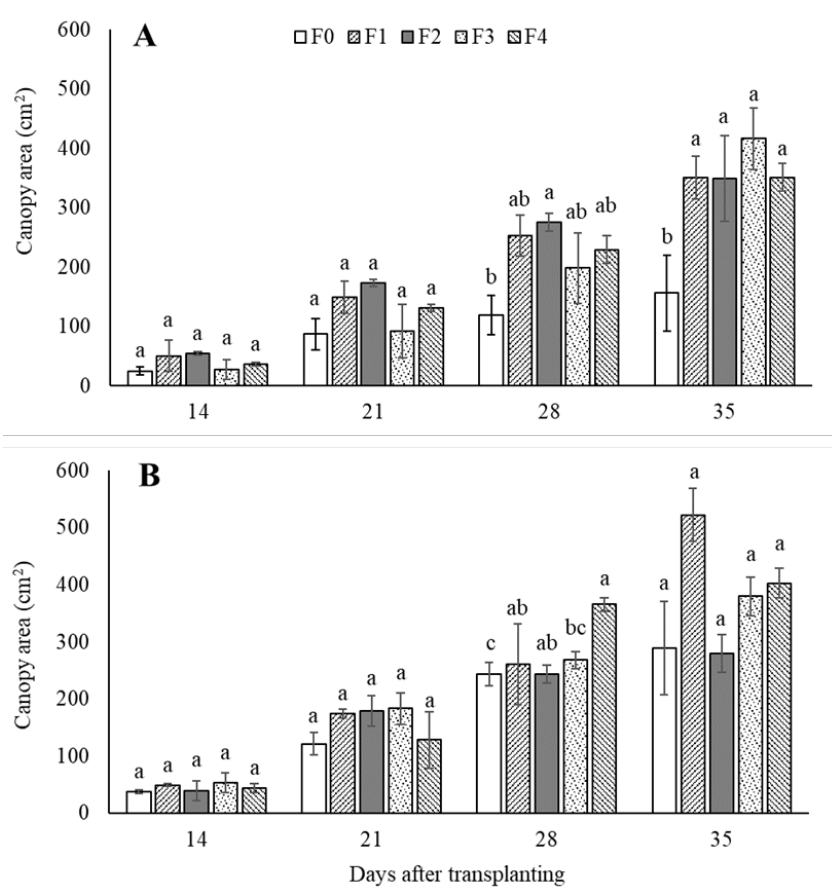

Figure 3 A) Canopy area in tatsoi grown using floating culture systems and B) conventional system. F0 $=$ unfertilized, F1 $=$ single, F2 = split into $2, \mathrm{~F} 3=$ split into 3 and F4 $=$ split into 4 applications. Vertical bars represent standard errors. Different letters within each clustered column from 14 to 35 DAT are significantly different at $p<0.05$.

Table 2 Pairwise comparison between floating and conventional cultivation on stem, leaf, and root dry weight for each split fertilizer treatment measured weekly from 14 to 35 DAT in tatsoi plant (Brassica rapa subsp. narinosa).

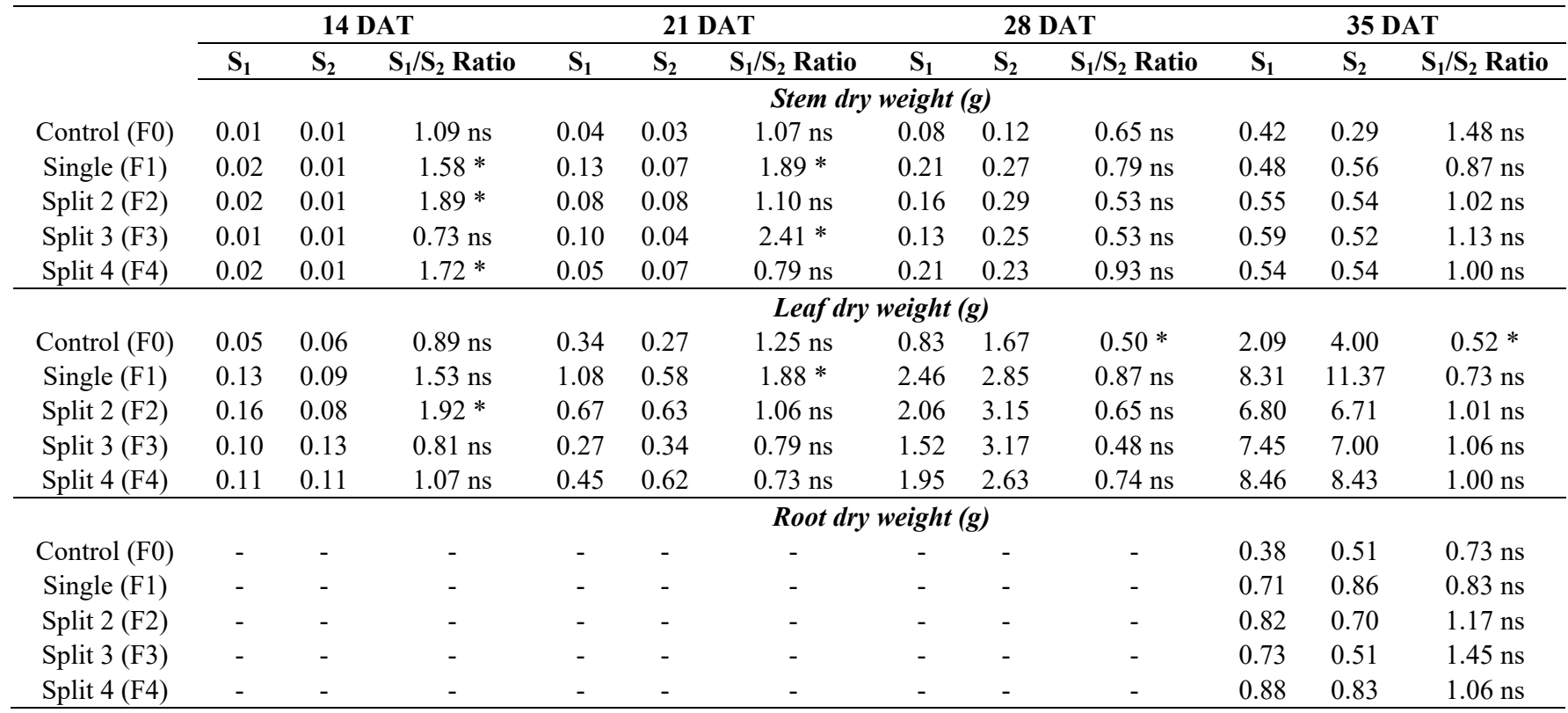

$\mathrm{DAT}=$ days after the first fertilizer application. S1 = floating culture. S2 = conventional system. Pairwise mean comparison was using the student's t-test. * = significantly different between each pair of S1 and S2 at $p<0.05$; ns $=$ not significantly different. 


\section{The effects of SPAD value}

Tatsoi is a leafy vegetable which can be harvested at any time during the vegetative growth stage after the plant has reached its marketable and profitable size. All parts of the above ground organs of tatsoi are consumable, consist of white stalks and green leaves. Tatsoi with a large number of leaves, high total leaf area, a wide canopy, and a bright green color was preferred by consumers; therefore, measurement of SPAD value is a significant part in assessing the quality of leafy vegetables, including tatsoi. The leaf SPAD value in tatsoi cultivated using a floating culture system was significantly higher than those cultivated using a conventional system, especially during early growth at 14 and 20 DAT. Differences in SPAD value in this study were mostly associated with split fertilizer application. Higher SPAD values were consistently observed in fertilizer applications split into 4 times (Table 3), spaced 10 days apart and beginning at 14 DAT. The F4 application evenly distributed nutrient availability throughout the growing process from 14 DAT until 38 DAT in the tatsoi plant.

\section{Growth analysis}

The Leaf Area Index (LAI), specific leaf area (SLA), and leaf area ratio (LAR) were not significantly different between floating culture and conventional practice, except for SLA at 14 DAT. It was interesting to note that SLA and LAR at harvest (35 DAT) in plants treated with single fertilizer application at the early vegetative stage (14 DAT) were significantly lower than split fertilizer applications. Some interaction between cultivation and fertilizer application methods were observed on LAI, SLA, and LAR. However, no specific pattern was recognizable (Table 4).

Table 3 The effect of different cultivation systems and split fertilizer applications on leaf SPAD value measured every 6 days from 14 to 38 DAT in tatsoi (Brassica rapa subsp. narinosa).

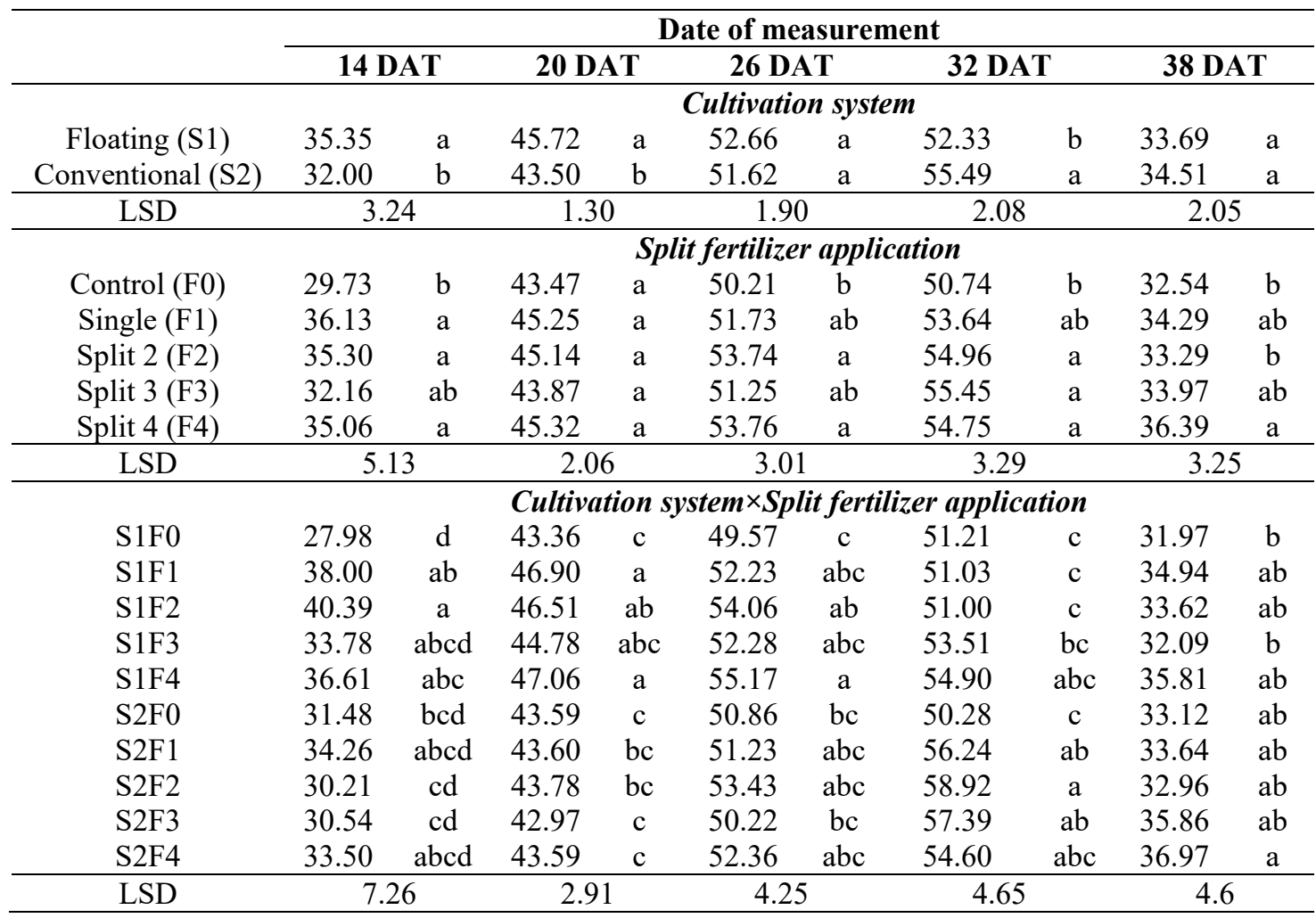

SPAD is a common proxy for leaf chlorophyll and nitrogen content. DAT $=$ days after the first fertilizer application. Mean values within each column and separated by treatments are not significantly different at $p<0.05$ if followed by the same letters. 
Table 4 The effect of different cultivation systems and split fertilizer applications on leaf area index (LAI), specific leaf area (SLA), and leaf area ratio (LAR) measured weekly from 14 to 35 DAT in tatsoi plant (Brassica rapa subsp. narinosa).

\begin{tabular}{|c|c|c|c|c|c|c|c|c|c|c|c|c|c|c|c|c|c|c|}
\hline & \multicolumn{4}{|c|}{14 DAT } & \multicolumn{4}{|c|}{21 DAT } & \multicolumn{4}{|c|}{28 DAT } & \multicolumn{6}{|c|}{35 DAT } \\
\hline & \multicolumn{2}{|c|}{ LAI } & \multicolumn{2}{|c|}{ SLA } & \multicolumn{2}{|c|}{ LAI } & \multicolumn{2}{|l|}{ SLA } & \multicolumn{2}{|c|}{ LAI } & \multicolumn{2}{|c|}{ SLA } & \multicolumn{2}{|c|}{ LAI } & \multicolumn{2}{|c|}{ SLA } & \multicolumn{2}{|c|}{ LAR } \\
\hline & \multicolumn{18}{|c|}{ Cultivation System } \\
\hline Floating & 0.58 & $\mathrm{a}$ & 228.09 & $\mathrm{a}$ & 0.96 & $\mathrm{a}$ & 163.26 & $\mathrm{a}$ & 1.72 & a & 212.22 & $\mathrm{a}$ & 2.17 & $\mathrm{a}$ & 111.38 & $\mathrm{a}$ & 91.81 & $\mathrm{a}$ \\
\hline Conventional & 0.52 & $\mathrm{a}$ & 187.19 & $\mathrm{~b}$ & 0.64 & $\mathrm{a}$ & 176.65 & $\mathrm{a}$ & 1.40 & a & 163.27 & $\mathrm{a}$ & 2.64 & $\mathrm{a}$ & 118.66 & $\mathrm{a}$ & 101.36 & $\mathrm{a}$ \\
\hline \multirow[t]{2}{*}{ LSD } & \multicolumn{2}{|l|}{0.21} & \multicolumn{2}{|c|}{38.96} & \multicolumn{2}{|c|}{0.57} & \multicolumn{2}{|l|}{36.255} & \multicolumn{2}{|c|}{0.48} & \multicolumn{2}{|c|}{120.11} & \multicolumn{2}{|c|}{0.64} & \multicolumn{2}{|c|}{19.33} & \multicolumn{2}{|c|}{16.32} \\
\hline & \multicolumn{18}{|c|}{ Split fertilizer application } \\
\hline Control (F0) & 0.49 & $\mathrm{a}$ & 218.86 & $\mathrm{a}$ & 1.00 & $\mathrm{a}$ & 153.28 & $\mathrm{a}$ & 1.52 & $\mathrm{a}$ & 172.38 & $\mathrm{a}$ & 2.02 & $\mathrm{a}$ & 119.05 & $\mathrm{a}$ & 93.03 & $a b$ \\
\hline Single (F1) & 0.61 & $\mathrm{a}$ & 236.75 & $\mathrm{a}$ & 0.73 & $\mathrm{a}$ & 153.28 & $\mathrm{a}$ & 1.34 & $\mathrm{a}$ & 166.19 & $\mathrm{a}$ & 2.93 & $\mathrm{a}$ & 81.34 & $\mathrm{~b}$ & 70.61 & $\mathrm{~b}$ \\
\hline Split 2 (F2) & 0.53 & $\mathrm{a}$ & 201.08 & $\mathrm{a}$ & 0.64 & $\mathrm{a}$ & 181.86 & $\mathrm{a}$ & 1.44 & $\mathrm{a}$ & 159.73 & $\mathrm{a}$ & 2.62 & $\mathrm{a}$ & 131.6 & $\mathrm{a}$ & 110.22 & $\mathrm{a}$ \\
\hline Split 3 (F3) & 0.53 & $\mathrm{a}$ & 204.68 & $\mathrm{a}$ & 1.09 & $\mathrm{a}$ & 178.24 & $\mathrm{a}$ & 1.79 & $\mathrm{a}$ & 148.23 & $\mathrm{a}$ & 2.18 & $\mathrm{a}$ & 124.77 & $\mathrm{a}$ & 108.76 & $\mathrm{a}$ \\
\hline Split 4 (F4) & 0.52 & $\mathrm{a}$ & 176.82 & $\mathrm{a}$ & 0.56 & $\mathrm{a}$ & 183.11 & $\mathrm{a}$ & 1.44 & a & 292.20 & $\mathrm{a}$ & 2.24 & $\mathrm{a}$ & 118.32 & $\mathrm{a}$ & 100.29 & $\mathrm{a}$ \\
\hline \multirow[t]{2}{*}{ LSD } & \multicolumn{2}{|l|}{0.33} & $61.5 \mathrm{~s}$ & & 0.9 & & 57.32 & & 1.7 & & 189.9 & & 1. & & 30.5 & & 25.8 & \\
\hline & & & & & & & Cultivatior & . & stem $\times$ & Split & tilizer a & 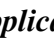 & & & & & & \\
\hline S1F0 & 0.58 & $\mathrm{a}$ & 188.46 & $a b$ & 1.44 & $\mathrm{a}$ & 162.59 & $\mathrm{a}$ & 1.44 & $a b$ & 160.3 & $a b$ & 1.53 & $\mathrm{c}$ & 108.65 & $a b c$ & 78.16 & $\mathrm{~cd}$ \\
\hline S1F1 & 0.58 & $\mathrm{a}$ & 207.71 & $a b$ & 0.97 & $\mathrm{a}$ & 140.27 & $\mathrm{a}$ & 1.20 & $a b$ & 166.7 & $a b$ & 2.11 & $\mathrm{bc}$ & 83.05 & $\mathrm{bc}$ & 71.71 & $\mathrm{~cd}$ \\
\hline S1F2 & 0.44 & $\mathrm{a}$ & 188.23 & $a b$ & 0.65 & $\mathrm{a}$ & 178.67 & $\mathrm{a}$ & 2.03 & $\mathrm{a}$ & 166.9 & $a b$ & 2.97 & $a b$ & 125.29 & $a b$ & 104.04 & acd \\
\hline S1F3 & 0.56 & $\mathrm{a}$ & 196.86 & $a b$ & 1.1 & $\mathrm{a}$ & 156.78 & $\mathrm{a}$ & 1.96 & $a b$ & 155.0 & $a b$ & 2.19 & $\mathrm{bc}$ & 122.46 & $a b c$ & 106.42 & $\mathrm{ac}$ \\
\hline S1F4 & 0.61 & a & 154.67 & $\mathrm{~b}$ & 0.67 & $\mathrm{a}$ & 177.99 & $\mathrm{a}$ & 1.95 & $a b$ & 413.2 & $\mathrm{a}$ & 2.01 & $\mathrm{bc}$ & 117.42 & $a b c$ & 98.69 & acd \\
\hline $\mathrm{S} 2 \mathrm{~F} 0$ & 0.41 & $\mathrm{a}$ & 249.78 & $\mathrm{a}$ & 0.57 & $\mathrm{a}$ & 143.37 & $\mathrm{a}$ & 1.59 & $a b$ & 184.5 & $a b$ & 2.51 & $a b c$ & 129.45 & $\mathrm{a}$ & 107.89 & $\mathrm{ac}$ \\
\hline $\mathrm{S} 2 \mathrm{~F} 1$ & 0.63 & $\mathrm{a}$ & 265.78 & $\mathrm{a}$ & 0.49 & $\mathrm{a}$ & 166.31 & $\mathrm{a}$ & 1.48 & $a b$ & 166.7 & $a b$ & 3.75 & $\mathrm{a}$ & 79.64 & $\mathrm{c}$ & 69.52 & $\mathrm{~d}$ \\
\hline $\mathrm{S} 2 \mathrm{~F} 2$ & 0.63 & $\mathrm{a}$ & 213.92 & $a b$ & 0.64 & $\mathrm{a}$ & 185.04 & $\mathrm{a}$ & 1.55 & $a b$ & 152.5 & $a b$ & 2.27 & $\mathrm{bc}$ & 137.91 & $\mathrm{a}$ & 116.39 & $\mathrm{a}$ \\
\hline S2F3 & 0.5 & $\mathrm{a}$ & 212.5 & $a b$ & 1.08 & $\mathrm{a}$ & 199.69 & $\mathrm{a}$ & 0.92 & $\mathrm{~b}$ & 141.5 & $\mathrm{~b}$ & 2.17 & $\mathrm{bc}$ & 127.07 & $\mathrm{a}$ & 111.1 & $\mathrm{a}$ \\
\hline $\mathrm{S} 2 \mathrm{~F} 4$ & 0.43 & $\mathrm{a}$ & 198.97 & $a b$ & 0.45 & $\mathrm{a}$ & 188.23 & $\mathrm{a}$ & 1.47 & $\mathrm{ab}$ & 171.2 & $\mathrm{ab}$ & 2.47 & $a b c$ & 119.21 & $a b c$ & 101.9 & acd \\
\hline LSD & 0.47 & & 87.10 & & 1.27 & & 81.069 & & 1.0 & & 268.5 & & 1. & & 43.22 & & 36.4 & \\
\hline
\end{tabular}

$\mathrm{DAT}=$ days after the first fertilizer application. Mean values within each column and separated by treatments are not significantly different at $p<0.05$ if followed by the same letters.

\section{Leaf area estimation models}

Based on the coefficient of determination $\left(R^{2}\right)$, the current study revealed that the quadratic regression model was reliable for estimating the leaf area of tatsoi. All models using a single predictor, i.e., petiole length, leaf thickness, leaf length (L), and leaf width (W) were developed using 0-intercept quadratic regression. Meanwhile, a double predictor $(\mathrm{L} \times \mathrm{W})$ was developed using 0 -intercept linear regression. Results indicated that all single predictor models gave a good leaf area estimate with the $R^{2}$ of $0.8169,0.7036,0.8800$ and 0.8820 , respectively. However, use of the double predictors with 0 -intercept linear regression exhibited a better $R^{2}$ value of 0.9720 (Figure 4). 

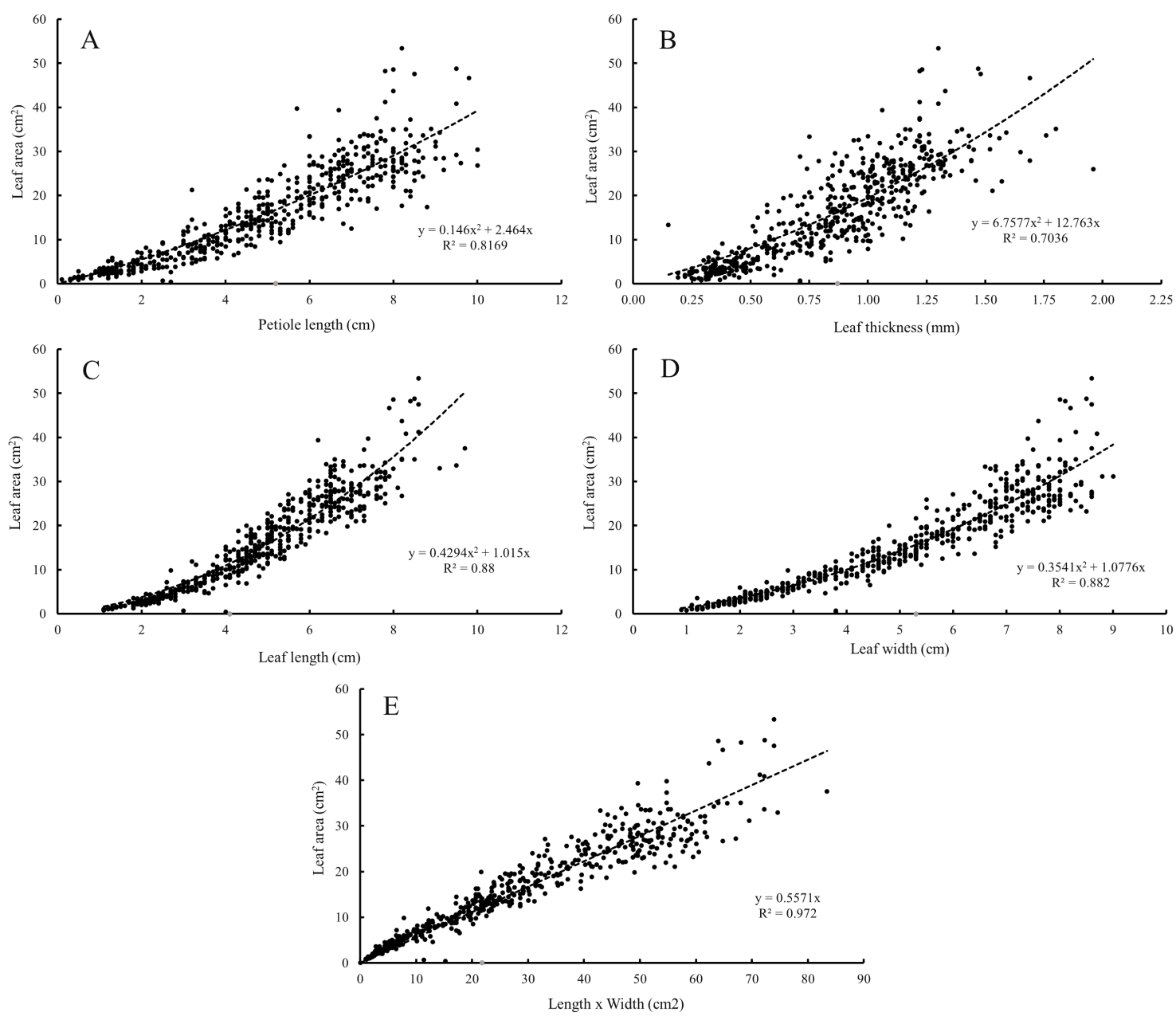

Figure $4 \mathrm{~A}$ ) Leaf area estimation in tatsoi (Brassica rapa subsp. narinosa) using petiole length, B) leaf thickness, C) leaf length, D) leaf width, E) leaf length $\times$ width as predictors fitted to 0 -intercept quadratic regression models $(\mathrm{ABCD})$ and linear model $(\mathrm{E})$.

Therefore, the 0 -intercept linear model using leaf length and leaf weight $(\mathrm{L} \times \mathrm{W})$ as predictors is recommended for non-destructive and accurate estimation of leaf area in the tatsoi plant. The leaf area estimation model is useful for studying plant growth, which requires periodic and non-destructive measurements of the same leaf over a specified period.

\section{Discussion}

\section{Cultivation system, growth, and SPAD value}

The early vegetative growth of tatsoi cultivated with a floating culture system was better than that cultivated with conventional practice. In floating culture, pots were managed such that the bottom part of the growing substrate continuously in direct contact with the water surface. Direct contact between the substrate and the water surface instigated upward water movement associated with capillary action $[14,20]$. This capillary action ensured water availability for plants to grow. This condition was beneficial for the growth of newly transplanted plants. The young plant has short roots and a small rhizosphere; therefore, its ability to absorb water was restricted within the limited volume of the substrate. Continuous water supply into the rhizosphere due to capillarity, as in the case of the floating culture system, maintained sufficient water availability for young tatsoi plants. At the early vegetative phase until 20 DAT, continuous water availability in floating culture leads to a higher number of leaves, total leaf area, dry weight, and SPAD value in the tatsoi plant.

Water is the most important factor influencing soil nutrient transport and plant growth. Grossnickle [21] reported that seedlings are usually exposed to stress due to the hydrologic cycle that limits water flows from the growing media to the roots. The optimum water availability in growing media fastened 
physiological processes which, in turn, accelerated plant growth. Brassica species require a high amount of water during cultivation. Growth and yield were severely reduced under limited water conditions $[22,23]$. Water availability determines the enlargement, division, and differentiation of cells. Furthermore, it also directly affected physiological, ecological and morphological events in plants [24].

Limited water availability at the initial stage ceased leaf formation and reduced the leaf number of brassica species [25]. Halted growth of leaf area under water stress conditions was due to a reduction in the total number of cells as mitotic activity of the epidermal cells decreased [26]. Leaf area reduction was the first process that occurred when the plant was imposed on limited water conditions [27]. Insufficient water availability limits the fixation of carbon dioxide because of the inactivation of photosynthetic enzymes and also causes lower leaf SPAD value [28].

The SPAD value determines leaf chlorophyll content using non-destructive methods that allow rapid and repeatable measurements over time [29]. Chlorophyll ( $a$ and b) acts as an intermediary in the transformation of the absorbed solar energy during photosynthesis [30]. The higher SPAD value of plants grown using a floating culture system was associated with a higher photosynthetic rate and produced higher dry weight. During photosynthesis, light energy is used to produce sugars that are subsequently converted to various organic compounds that constitute approximately $95 \%$ of the plant's dry mass [31].

Since tatsoi is a leafy vegetable; therefore, this study only focused on the vegetative stage of tatsoi growth until marketable size reached. Photosynthates during the vegetative growth stage are mainly translocated to the shoot (stem and leaves). Leaf SPAD values peaked at 26 and 32 DAT, then decreased at 38 DAT, indicating synthesis, accumulation, and degradation of leaf chlorophyll.

\section{Split fertilizer application}

In addition to water availability, better plant growth was secured by nutrient supply to growing media. Nitrogen, phosphorus, and potassium should be sufficiently available to plants for the continuation of their metabolic processes [32]. The overall growth of tatsoi plants was inhibited if they were cultivated in deprived soil without additional fertilizer application. When N, P, or K were not included in the applied fertilizer, shoot and root growth in the brassica family was significantly reduced [33,34]The addition of 6 $\mathrm{g} /$ plant NPK fertilizer in this study improved leaf related growth and dry biomass in the tatsoi plant. Tasnim et al. [35] also reported that additional NPK nutrients stimulated plant growth and produced a higher number of leaves, leaf area index (LAI) and chlorophyll content. $\mathrm{N}$ and $\mathrm{P}$ were essential components of proteins, amino acids, nucleic acids, phospholipids, metabolic compounds, and enzymatic processes, respectively, whereas $\mathrm{K}$ was involved in water and nutrient absorption, transpiration, enzymatic activity, and carbohydrate translocation [36].

This study revealed that deceleration of plant growth at a later stage was observed in plants treated with a single fertilizer application on the day of transplanting. This implies that nutrients applied at an early vegetative stage have been diminished after 21 days of application; therefore, shoot growth has been slowed down due to lower nutrient availability. According to Azarpour et al. [37], maximum growth occurred at the early growth stage of the plant and decreased accordingly as nutrient availability lessened. The reduction of soil nutrients was associated with absorption by plants and loss through leaching [38]. Soon after application, a single fertilizer application increased the possibility of nutrient loss from the rhizosphere since the amount of available fertilizer was higher than the absorbing capacity of young plant roots [8].

Although fertilizer is very important for plant growth, fertilizer applications must be optimized for efficiency and minimized negative impact on the environment [38]. Plant nutrients are highly mobile and easily lost in soil, potentially causing a financial loss to the farmer and potentially wreaking havoc on the environment if not managed properly [39]. Split fertilizer application was one of the methods for improving nutrient efficiency by reducing nutrient loss. However, for crops with a short life or production cycle, such as tatsoi, a single application of NPK fertilizer was proven to be sufficient to support their growth until harvest.

\section{Leaf area estimation model}

The leaf area of a plant can be measured by destructive or non-destructive methods. However, destructive methods are not viable for successive measurements of the same leaf over time [41,42]. Leaf area estimation using regression models has been developed for calculating leaf area using predictors without excision. Non-destructive leaf area measurement could be applied for a wide range of plants [42]. Leaf area estimation has been done in some species of the Brassicaceae family, i.e., pakchoi ( $B$. campestris) [43], rapeseed (B. napus) [44], red cabbage (B. oleracea var. capitata), cabbage (B. oleracea var. capitata) and broccoli (B. oleracea var. Italica) [40]. 
The common predictors used for leaf area estimation models include petiole length, leaf width, leaf length, main and/or lateral vein length, leaf thickness, and combinations of these morphological traits. In this study, quadratic regression models using leaf width, leaf length, or a combination of these as predictors were proven to be accurate. A similar result was reported by Olfati et al. [41] who found that leaf width was an acceptable predictor for leaf area estimation in red cabbages, white cabbages, and broccoli. A linear and polynomial model using $\mathrm{L} \times \mathrm{W}$ as a predictor was the best for estimating the leaf area of pistachios (Pistacia vera L. 'Badami') [45]. The best leaf area estimation model was usually determined by comparing several different equations [41,46-48].

\section{Conclusions}

Tatsoi is a promising vegetable for cultivation using floating and conventional systems in the riparian wetland ecosystem. Yet, only floating culture can be employed during the flooding period. The floating culture system has an additional advantage of securing sufficient water supply throughout the growing period because of the continuous upward water movement in the substrate, owing to capillarity force. The application of NPK fertilizer is necessary for obtaining optimum growth of tatsoi. The application of $6 \mathrm{~g} \mathrm{NPK}$ on the day of transplanting enables sufficient nutrients until harvest. Yet, split fertilizer application resulted in higher SPAD value, which is directly associated with greener leaves, one of the quality traits desired by the majority of leaf vegetable consumers. The 0 -intercept linear regression model is recommended for leaf area estimation in tatsoi using a combination of the leaf length and width $(\mathrm{L} \times \mathrm{W})$ as a predictor.

\section{Acknowledgements}

We deeply appreciate the editorial team of this journal for their very kind attention and superb supports. We also would like to express our gratitude to the anonymous reviewers for their comments and suggestions.

\section{References}

[1] AM Artemyeva and AE Solovyeva. Quality evaluation of some cultivar types of leafy Brassica rapa. Acta Hortic. 2006; 706, 121-8.

[2] R Soare, D Maria, C Babeanu, and M Popescu. Antioxidant enzyme activities of some brassica species. Bull. Univ. Agr. Sci. Vet. Med. Cluj-Napoca Hortic. 2017; 74, 191.

[3] KA Bird, H An, E Gazave, MA Gore, JC Pires, LD Robertson and JA Labate. Population structure and phylogenetic relationships in a diverse panel of Brassica rapa L. Front. Plant Sci. 2017; 8, 321.

[4] P Deepa, K Sowndhararajan and SJ Park. Polyphenolic contents and antioxidant activity of brassicaceae sprouts cultivated in the plant factory system. J. Agr. Life Environ. Sci. 2020; 32, 32131.

[5] A Virsilè, A Brazaitytè, J Jankauskienè, J Miliauskienè, V Vaštakaitè, I Odminytè, A Novickovas and G Samuolienė. Pre-harvest LED lighting strategies for reduced nitrate contents in leafy vegetables. Zemdirbyste Agr. 2018; 105, 249-56.

[6] S Clark and M Cavigelli. Suitability of composts as potting media for production of organic vegetable transplants. Compost Sci. Utilization 2005; 13, 150-5.

[7] B Lakitan, B Hadi, S Herlinda, E Siaga, LI Widuri, K Kartika, L Lindiana, Y Yunindyawati and M Meihana. Recognizing farmers' practices and constraints for intensifying rice production at riparian wetlands in Indonesia. NJAS Wageningen J. Life Sci. 2018; 85, 10-20.

[8] K Kartika, B Lakitan, N Sanjaya, A Wijaya, S Kadir, A Kurnianingsih, LI Widuri, E Siaga and M Meihana. Internal versus edge row comparison in Jajar legowo 4:1 rice planting pattern at different frequency of fertilizer applications. AGRIVITA J. Agr. Sci. 2018; 40, 222-32.

[9] B Lakitan, H Iwanaga, K Kartika, H Kriswantoro and JI Sakagami. Adaptability to varying water levels and responsiveness to NPK fertilizer in yellow velvetleaf plant (Limnocharis flava). Aust. J. Crop Sci. 2018; 12, 1757-64.

[10] J Feng, HA Hussain, S Hussain, C Shi, L Cholidah, S Men, J Ke and L Wang. Optimum water and fertilizer management for better growth and resource use efficiency of rapeseed in rainy and drought seasons. Sustainability 2020; 12, 703.

[11] E Siaga, B Lakitan, H Hasbi, SM Bernas, LI Widuri and K Kartika. Floating seedbed for preparing rice seedlings under unpredictable flooding occurrence at tropical riparian Wetland. Bulg. J. Agr. Sci. 2019; 25, 326-36. 
[12] F Ramadhani, B Lakitan and M Hasmeda. Decaying utricularia-biomass versus soil-based substrate for production of high quality pre-transplanted rice seedlings using floating seedbeds. Aust. J. Crop Sci. 2018; 12, 1983-8.

[13] KK Jaya, B Lakitan and ZP Negara. Depth of water-substrate interface in floating culture and nutrient-enriched substrate effects on green apple eggplant. AGRIVITA J. Agr. Sci. 2019; 41, 230-7.

[14] E Siaga, B Lakitan, Hasbi, M Bernas, A Wijaya, R Lisda, F Ramadhani, LI Widuri, K Kartika and M Meihana. Application of floating culture system in chili pepper (Capsicum annum L.) during prolonged flooding period at riparian wetland in Indonesia. Aust. J. Crop Sci. 2018; 12, 808-16.

[15] B Lakitan and E Siaga. 2019, Floating raft constructed using used plastic bottle for rice seedling preparation, Granted Patent IDP000065141.

[16] S Hasan, A Mohammad, M Ghosh and M Khalil. Assessing of farmers' opinion towards floating agriculture as a means of cleaner production: A case of Barisal District, Bangladesh. Br. J. Appl. Sci. Tech. 2017; 20, 1-14.

[17] HM Easlon and AJ Bloom. Easy leaf area: Automated digital image analysis for rapid and accurate measurement of leaf area. Appl. Plant Sci. 2014; 2, 1400033.

[18] LI Widuri, B Lakitan, M Hasmeda, E Sodikin, A Wijaya, M Meihana, K Kartika and E Siaga. Relative leaf expansion rate and other leaf-related indicators for detection of drought stress in chili pepper (Capsicum annuum L.). Aust. J. Crop Sci. 2017; 11, 1617-25.

[19] M Meihana, B Lakitan, MU Harun, LI Widuri, K Kartika, E Siaga and H Kriswantoro. Steady shallow water table did not decrease leaf expansion rate, specific leaf weight, and specific leaf water content in tomato plants. Aust. J. Crop Sci. 2017; 11, 1635-41.

[20] NPK Semananda, JD Ward and BR Myers. A semi-systematic review of capillary irrigation: The benefits, limitations, and opportunities. Horticulturae 2018; 4, 23.

[21] SC Grossnickle. Importance of root growth in overcoming planting stress. New Forest. 2005; 30, 273-94.

[22] M Saeed, N Ilyas, A Akram, N Raja, R Mazhar, F Bibi, W Seerat, S Kanwal and N Batool. Effect of drought stress on Brassica crops and its mitigation by inoculation of PGPR. Int. J. Biosci. 2016; 9, 282-91.

[23] S Yu, F Zhang, Y Yu, D Zhang, X Zhao and W Wang. Transcriptome profiling of dehydration stress in the Chinese cabbage (Brassica rapa L. ssp. pekinensis) by tag sequencing. Plant Mol. Biol. Rep. 2012; 30, 17-28.

[24] A Chadha, SK Florentine, BS Chauhan, B Long and M Jayasundera. Influence of soil moisture regimes on growth, photosynthetic capacity, leaf biochemistry and reproductive capabilities of the invasive agronomic weed; Lactuca serriola. PLoS One. 2019; 14, e0128191.

[25] E Ackah and R Kotei. Effect of drought length on the performance of cabbage (Brassica oleracea var capitata) in the forest-savannah transition zone, Ghana. Plant Physiol. Rep. 2021; 26, 74-83.

[26] G Koch, G Rolland, M Dauzat, A Bédiée, V Baldazzi, N Bertin, Y Guédon and C Granier. Leaf production and expansion: A generalized response to drought stresses from cells to whole leaf biomass - a case study in the tomato compound leaf. Plants 2019; 8, 409.

[27] AS Sacita, T June and I Impron. Soybean adaptation to water stress on vegetative and generative phases. Agrotech J. 2018; 3, 42-52.

[28] Shahenshah and A Isoda. Effects of water stress on leaf temperature and chlorophyll fluorescence parameters in cotton and peanut. Plant Prod. Sci. 2010; 13, 269-78.

[29] CC Sim, AR Zaharah, MS Tan and KJ Goh. Rapid determination of leaf chlorophyll concentration, photosynthetic activity and NK concentration of Elaies guineensis via correlated SPAD-502 chlorophyll index. Asian J. Agr. Res. 2015; 9, 132-8.

[30] D Pavlovic, B Nikolic, S Djurovic, H Waisi, A Andjelkovic and D Marisavljevic. Chlorophyll as a measure of plant health: Agroecological aspects. Pesticidi Fitomedicina 2014; 29, 21-34.

[31] FS Chapin and VT Eviner. Biogeochemical interactions governing terrestrial net primary production. In: HD Holland and KK Turekian (Eds.). Treatise on geochemistry. $2^{\text {nd }}$ ed. Elsevier, Oxford, 2014, p. 190-216.

[32] JC Cole, MW Smith, CJ Penn, BS Cheary and KJ Conaghan. Nitrogen, phosphorus, calcium, and magnesium applied individually or as a slow release or controlled release fertilizer increase growth and yield and affect macronutrient and micronutrient concentration and content of field-grown tomato plants. Sci. Hortic. 2016; 211, 420-30.

[33] HJD Almeida, MV Carmona, VS Cavalcante, ABC Filho, RPD Mello, RA Flores, BMMN Borges and M Mauad. Nutritional and visual diagnosis in broccoli (Brassica oleracea var. italica 1.) plants: 
Disorders in physiological activity, nutritional efficiency and metabolism of carbohydrates. Agronomy 2020; 10, 1572.

[34] MNA Naher, MN Alam and N Jahan. Effect of nutrient management on the growth and yield of cabbage (Brassica oleracea var. capitata L.) in calcareous soils of Bangladesh. Agr. 2015; 12, 2433.

[35] R Tasnim, JL Coo, CWW Ng and V Capobianco. Soil nutrient effects on suction and volumetric water content in heavily compacted vegetated soil. In: Proceedings of the China-Europe Conference on Geotechnical Engineering, Vienna, Austria. 2016.

[36] T Ohyama. Nitrogen as a major essential element of plants. In: T Ohyama and K Sueyoshi (Eds.). Nitrogen assimilation in plants. $1^{\text {st }}$ ed. Research Signpost, Kerala, 2010, p. 16.

[37] E Azarpour, M Moraditochaee and HR Bozorgi. Effect of nitrogen fertilizer management on growth analysis of rice cultivars. Int. J. Biosci. 2014; 4, 35-47.

[38] W Widowati and A Asnah. Biochar effect on potassium fertilizer and leaching potassium dosage for two corn planting seasons. AGRIVITA J. Agr. Sci. 2014; 36, 65-71.

[39] JK Schjoerring, I Cakmak and PJ White. Plant nutrition and soil fertility: Synergies for acquiring global green growth and sustainable development. Plant Soil 2019; 434, 1-6.

[40] JN Chianu, JN Chianu and F Mairura. Mineral fertilizers in the farming systems of Sub-Saharan Africa. A review. Agron. Sustain. Dev. 2012; 32, 545-66.

[41] JA Olfati, G Peyvast, H Shabani and Z Nosratie-Rad. An estimation of individual leaf area in cabbage and broccoli using non-destructive methods. J. Agr. Sci. Tech. 2010; 12, 627-32.

[42] FA Khan, FA Banday, S Narayan, FU Khan and SA Bhat. Use of models as non-destructive method for leaf area estimation in horticultural crops. IRA Int. J. Appl. Sci. 2016; 4, 162-80.

[43] YY Cho and JE Son. Estimation of leaf number and leaf area of hydroponic pak-choi plants (Brassica campestris ssp. chinensis) using growing degree-days. J. Plant Biol. 2007; 50, 8.

[44] GA Dalmago, CAM Bianchi, S Kovaleski and E Fochesatto. Evaluation of mathematical equations for estimating leaf area in rapeseed. Rev. Cienc. Agron. 2019; 50, 420-30.

[45] S Karimi, V Tavallali, M Rahemi, AA Rostami and M Vaezpour. Estimation of leaf growth on the basis of measurements of leaf lengths and widths, choosing pistachio seedlings as model. Aust. J. Basic Appl. Sci. 2009; 3, 1070-5.

[46] JOD Carvalho, M Toebe, FL Tartaglia, CT Bandeira and AL Tambara. Leaf area estimation from linear measurements in different ages of Crotalaria juncea plants. Ann. Brasz. Acad. Sci. 2017; 89, 1851-68.

[47] D Khan, MJ Zaki and SM Abbas. Leaf area estimation in Jojoba (Simmondsia chinensis (Link.) CE Schneider) seedlings. Int. J. Biol. Biotechnol. 2015; 12, 667-74.

[48] M Souza and C Amaral. Non-destructive linear model for leaf area estimation in Vernonia ferruginea Less. Braz. J. Biol. 2015; 75, 152. 